\title{
COMPARATIVE STUDY ON EFFICACY OF KETOROLAC AND PETHIDINE FOR POSTOPERATIVE PAIN MANAGEMENT
}

\author{
Laxmi Shrestha ${ }^{1}$, Bishal Joshi ${ }^{2}$, Anjan Palikhey ${ }^{3}$, Kushal Bhattarai $^{4}$
}

\begin{abstract}
INTRODUCTION

Postoperative pain management is essential for early mobilization and rehabilitation to enhance recovery and to reduce morbidity. Ketorolac and pethidine are two most common analgesics used in the postoperative setting for pain management.
\end{abstract}

\section{MATERIAL AND METHODS}

Sixty patients $(n=60)$ of age group 18-60 years who undergone various surgical procedures were divided randomly into two groups (T1 and T2). T1 group received inj. ketorolac $5 \mathrm{mg} / \mathrm{kg}$ IM and T2 group received pethidine $1.5 \mathrm{mg} / \mathrm{kg} \mathrm{IM} \mathrm{body}$ weight respectively on 6 hourly basis for 48 hours postoperatively. Patients were assessed in the recovery room for pain according to Visual Analogue Scale (VAS), Verbal Rating Scale (VRS) and Sedation Score after 1, 6, 12, 18, 24 and 48 hours of drug administration. Analgesic efficacy was measured using VAS and VRS. Safety of the drugs was assessed by using Sedation Score.

\section{RESULTS}

Ketorolac showed equianalgesic effect as pethidine estimated by VAS score at $18^{\text {th }}$ and $48^{\text {th }}$ hour. In other periods of observation, pethidine exhibited better analgesic effects than ketorolac. However, ketorolac shows less incidence of sedation compared to pethidine.

\section{CONCLUSION}

This study showed that postoperative pain during the first 48 hours can be relieved by either ketorolac or pethidine. Ketorolac appeared safer than pethidine while pethidine appeared more effective analgesic than ketorolac in the management of postoperative pain.

KEY WORDS Ketorolac, pethidine, postoperative pain, visual analogue scale

1. Department of Pharmacology, Universal College of Medical Sciences Bhairahawa, Nepal

2. Department of Physiology, Universal College of Medical Sciences Bhairahawa, Nepal

3. Department of Pharmacology, College of Medical Sciences, Bharatpur, Chitwan, Nepal

4. Department of Biochemistry, College of Medical Sciences, Bharatpur, Chitwan, Nepal

DOI: https://doi.org/10.3126/jucms.v7i1.24682

\author{
For Correspondence \\ Dr. Bishal Joshi \\ Department of Physiology \\ Universal College of Medical Sciences \\ Bhairahawa, Nepal \\ Email: drbishaljoshi76@gmail.com
}




\section{INTRODUCTION}

International Association for the Study of Pain has defined pain as "an unpleasant sensory and emotional experience associated with actual or potential tissue damage or described in terms of such damage" ${ }^{\text {P }}$ Postoperative pain is considered a form of acute pain due to surgical trauma with an inflammatory reaction and initiation of an afferent neuronal barrage. It is combined constellation of several unpleasant sensory, emotional and mental experience precipitated by the surgical trauma and associated with autonomic, endocrine metabolic, physiological and behavioral responses. ${ }^{2}$ A number of drugs are available for the management of postoperative pain. Opioids are widely used analgesics for postoperative pain but are not free from side effects like respiratory depression, sedation and protracted vomiting. ${ }^{3}$ Pethidine is a synthetic opioid (opium derived) analgesic which was first synthesized in 1939 as a potential anticholinergic agent by German chemist Otto Eisleb and its analgesic properties were first recognized by Otto Schaumann: Originally intended as an antispasmodic/antidiarrheal medicine, this drug was soon noted for its analgesic properties and was rapidly introduced into obstetric medicine. ${ }^{4}$ Pethidine is indicated for the treat ment of moderate to severe pain, and is delivered as a hydrochloride salt in tablets, as a syrup, or by intramuscular, subcutaneous or intravenous injection.

In addition to opioids, effectiveness of non-steroidal antiinflammatory drugs (NSAIDs), e.g. ketorolac, diclofenac, ibuprofen, indomethacin, and tenoxicam in management of postoperative pain has been confirmed. Ketorolac trometha mine is a NSAID with a potent analgesic and low incidence of side effects. Ketorolac does not depress ventilation and is not associated with nausea, vomiting, urinary retention, sedation and itching and it reduces postoperative opiate requirements. ${ }^{6}$ Moreover, it has been successfully used to replace opioid in some situations involving mild to moderate postsurgical pain.

Pethidine is commonly used postoperative opioid analgesic, and ketorolac is a newer non-steroidal anti-inflammatory drug (NSAID), licensed for short term use in the management of moderate to severe postoperative pain. Pethidine are used routinely to alleviate pain. Though, it has several troublesome side effects. Its administration is associated with a high incidence of nausea and vomiting, gastrointestinal upset. The narcotic activity of pethidine also induces a degree of sedation. $^{7}$

Various studies have been performed to compare the analgesic efficacy and sedative effect of ketorolac and pethidine. Plethora of results in these studies has suggested mixed findings. In some studies, pethidine was found to be an effective analgesic compared to ketorolac. ${ }^{8-11}$ In other studies, ketorolac was found to be superior for the management of postoperative pain. ${ }^{12-17}$ In still other studies, ketorolac was found to have similar analgesic efficacy compared to pethidine. ${ }^{18-23}$ Moreover, combination of ketorolac and pethidine was better compared to single drug. Likewise, in many studies, the sedative effect of ketorolac was found less compared to pethidine..$^{22,23}$

However, the availability of data related to analgesic efficacy and safety of ketorolac and pethidine in postoperative pain management in our country is not adequate. In addition, no comparative study has been conducted to see such parameters after major surgeries. In this pretext, the present study was conducted to compare the analgesic efficacy and safety of ketorolac and pethidine in postoperative pain relief after major surgeries.

\section{MATERIAL AND METHODS}

\section{Study design}

This hospital based longitudinal prospective study was conducted at College of Medical Sciences Teaching Hospital (CMSTH), Bharatpur-10, Chitwan during the period from March 2013 to August 2014. Ethical clearance was taken from institutional review committee (IRC) of CMS-TH. The sample size of 60 patients attending the Surgery department and who underwent various surgeries and required postoperative pain management was included for the study. All the participants were provided with verbal information regarding study protocol and consent form was signed to participate in the study. The overall plan was to manage the postoperative pain. Additionally, selection was done on the basis of fulfillment of the inclusion and exclusion criteria.

\section{Inclusion Criteria}

1. Patients of both gender aged $18-60$ years

2. Patients willing to undergo for the study

3. Patients undergoing various major surgical procedures (at the department of surgery), such as:

\subsection{Appendicectomy \\ 3.2. Laparotomy \\ 3.3. Cholecystectomy \\ 3.4. Tonsillectomy}

\section{Exclusion Criteria}

1. History of convulsion disorders

2. Sensitivity to NSAIDS

3. Presence of respiratory problems, cyanotic appearance and increased bronchial secretions

4. Addiction to narcotics

5. Patients on anticoagulant therapy 
All the patients undergone various surgeries were randomly divided into two treatment groups: Treatment Group One (T1) and Treatment Group Two (T2). Sample size was measured as 30 patients in each group. T1 group included the patient receiving ketorolac $5 \mathrm{mg} / \mathrm{kg}$ body weight IM every six hourly for 48 hours in the post-operative period, and T2 group include the patient receiving pethidine $1.5 \mathrm{mg} / \mathrm{kg}$ body weight IM repeated every six hours for 48 hours in the postoperative period $^{7}$

Patients were informed about the possible side effects of drug. Sample was selected randomly as lottery method.

\section{Assessment of subjects}

Analgesic efficacy of both drugs in the groups T1 and group T2 was measured by Visual Analogue Scale (VAS) and Verbal Rating Scale (VRS). The safety of the drugs was measured by Sedation Score (SS). VAS, VRS and SS were recorded at 1, 6, $12,18,24$ and 48 hours postoperatively.

\section{Visual Analogue Scale}

In this technique, a $10 \mathrm{~cm}$ long scale ranged from 0-10 marks was shown to the patients where 0 marks represents no pain and 10 mark represents worst possible pain. Patient was explained to represent at ' 0 ' for "no pain at all" and at '10' for "pain as bad as could possibly imagine" and was asked to mark the point of the scale where his/her pain lies which corresponds to the numerical index of the severity of the pain.

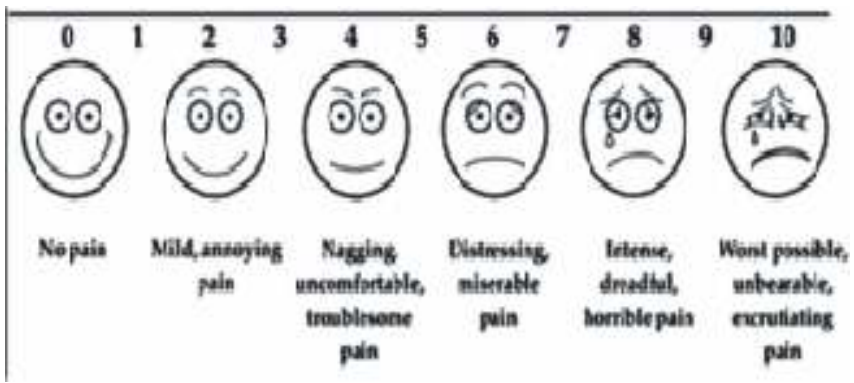

Figure 1. Visual analogue scale

\section{Verbal Rating Scale (VRS)}

The 5 point VRS was employed in this study. Verbal Rating Scale consists of a series of words subjectively describing pain intensity and unpleasant experiences. The patient is asked to select one adjective that best describes his/her pain or feeling. As per the description the patient is classified into no pain, mild, moderate, severe pain category which is numbered 2,4 , 6,8 and 10 respectively.
According to 5 point VRS, pain is assessed based on following criteria:

Score $2=$ no pain,

Score $4=$ mild pain,

Score $6=$ moderate pain

Score $8=$ severe pain,

Score $10=$ very severe pain/over whelming pain (the worst pain you can imagine).

Here, the patients were asked to describe the degree of their discomfort by choosing one of the vertical lines that corresponds to the intensity of pain that they have experienced.

\section{Sedation Score}

Assessment of sedation was done using 4 point scale as follows

\begin{tabular}{ll}
\hline Degree of sedation & Score \\
\hline Asleep & 3 \\
Moderate drowsiness & 2 \\
Mild drowsiness & 1 \\
Awake & 0 \\
\hline
\end{tabular}

Pain and sedation assessment was done at 1 hrs, 6 hrs, 12 hrs, $18 \mathrm{hrs}, 24 \mathrm{hrs}, 48 \mathrm{hrs}$ after each dose of study drugs. During the night time when the patients were on natural sleep pain assessment was not done.

\section{Statistical Analysis}

Statistical analysis was done by SPSS 20.0 version (Statistical Package for Social Science for Windows Version). Results on continuous measurements were presented as Mean \pm SD and results on categorical measurement were presented in number and percentage $(\%)$. Independent t-test was used to compare the means of VAS and SS between the two different groups of patients. Comparison was done at $95 \%$ confidence interval of the distribution of the data and $\mathrm{p}$ value $<0.05$ was considered statistically significant.

\section{RESULTS}

There were total 60 participants in the study ranging from 18 60 years. Among them 27 (45\%) were males and 33 (55\%) were females. They underwent various surgical procedures such as, appendectomy (16), cholecystectomy (14), laparotomy (13), tonsillectomy (9) and others (8). The analgesic efficacy (VAS score) and sedation score of ketorolac and pethidine were compared by administering these drugs postoperatively as (ketorolac, 30 patients) and (pethidine, 30 patients). The VAS score and sedation score of each patient 
were recorded at 1 hour, 6 hours, 12 hours, 18 hours, 24 hours and 48 hours post drug administration.

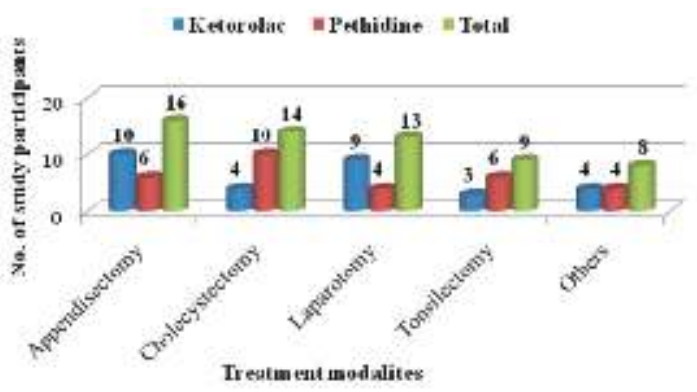

Figure 2. Bar diagram showing treatment modalities and treatment group

As shown in the figure 2, most of the patients who underwent Appendectomy and laparotomy, received ketorolac. On the other hand, pethidine was administered to most of the patients who under went cholecystectomy.

Table 1. Descriptive statistics of total patients for different parameters

\begin{tabular}{lcccc}
\hline Variables & Mean & $\begin{array}{c}\text { Standard } \\
\text { Deviation (SD) }\end{array}$ & Minimum & Maximum \\
\hline Age (years) & 38.92 & 12.42 & 18.0 & 59.0 \\
VAS 1-Hr & 4.60 & 1.29 & 2.0 & 8.0 \\
VAS 6-Hr & 4.00 & 1.16 & 2.0 & 6.0 \\
VAS 12- & 3.00 & 1.19 & 2.0 & 6.0 \\
$\begin{array}{l}\text { Hr } \\
\text { VAS 18- }\end{array}$ & 2.20 & 0.61 & 2.0 & 4.0 \\
$\begin{array}{l}\text { Hr } \\
\text { VAS 24- }\end{array}$ & 2.40 & 0.81 & 2.0 & 4.0 \\
$\begin{array}{l}\text { Hr } \\
\text { VAS 48- }\end{array}$ & 2.20 & 0.61 & 2.0 & 4.0 \\
Hr & & &
\end{tabular}

Table 2. Comparison of means of different parameters between study participants who were given ketorolac Vs pethidine

\begin{tabular}{ccccc}
\hline \multirow{2}{*}{ Variables } & $\begin{array}{c}\text { Treatment } \\
\text { Groups }\end{array}$ & Mean \pm SD & \multicolumn{2}{c}{ Independent test } \\
\cline { 3 - 5 } & & t-value & p-value \\
\hline \multirow{2}{*}{ Age (years) } & Ketorolac & $38.03 \pm 12.32$ & -0.55 & 0.59 \\
& Pethidine & $39.80 \pm 12.66$ & & \\
& Ketorolac & $5.07 \pm 1.26$ & 2.98 & 0.004 \\
VAS 1-Hr & Pethidine & $4.13 \pm 1.17$ & & \\
& Ketorolac & $4.53 \pm 0.89$ & 3.97 & 0.000 \\
VAS 6-Hr & Pethidine & $3.47 \pm 1.17$ & & \\
& Ketorolac & $3.60 \pm 1.10$ & 4.48 & 0.000 \\
VAS 12-Hr & Pethidine & $2.40 \pm 0.97$ & & \\
& Ketorolac & $2.20 \pm 0.61$ & 0.00 & 1.000 \\
VAS 18-Hr & Pethidine & $2.20 \pm 0.61$ & & \\
& Ketorolac & $2.67 \pm 0.96$ & 2.69 & 0.009 \\
VAS 24-Hr & Pethidine & $2.13 \pm 0.50$ & & \\
& Ketorolac & $2.33 \pm 0.76$ & 1.74 & 0.088 \\
VAS 48-Hr & $\begin{array}{l}\text { Pethidine } \\
2.06 \pm 0.36\end{array}$
\end{tabular}

As depicted in the table 2, patients who received ketorolac had significantly higher mean visual analogue scale score compared to pethidine group at all time, except for 18 hours and 48 hours postoperatively.

Table 3. Comparison of incidence of side effect (sedation) between patients treated with ketorolac and pethidine at 1 , $6,12,18,24,48$ hours postoperatively using chi-square test

\begin{tabular}{|c|c|c|c|c|c|}
\hline \multirow{2}{*}{$\begin{array}{l}\text { Postoperative } \\
\text { time (in hours) }\end{array}$} & \multirow{2}{*}{$\begin{array}{c}\text { Sedation } \\
\text { score }\end{array}$} & \multicolumn{2}{|c|}{ Treatment group } & \multirow{2}{*}{ Total } & \multirow{2}{*}{ p-value } \\
\hline & & Ketorolac & Pethidine & & \\
\hline \multirow{4}{*}{1} & 0 & 24 & 16 & 40 & \multirow{4}{*}{0.061} \\
\hline & 1 & 6 & 12 & 18 & \\
\hline & 2 & 0 & 2 & 2 & \\
\hline & Total & 30 & 30 & 60 & \\
\hline \multirow{4}{*}{6} & 0 & 25 & 17 & 42 & \multirow{4}{*}{0.045} \\
\hline & 1 & 5 & 10 & 15 & \\
\hline & 2 & 0 & 3 & 3 & \\
\hline & Total & 30 & 30 & 60 & \\
\hline \multirow{3}{*}{12} & 0 & 26 & 17 & 43 & \multirow[t]{3}{*}{0.010} \\
\hline & 1 & 4 & 13 & 17 & \\
\hline & Total & 30 & 30 & 60 & \\
\hline \multirow{3}{*}{18} & 0 & 27 & 16 & 43 & \multirow[t]{3}{*}{0.002} \\
\hline & 1 & 3 & 14 & 17 & \\
\hline & Total & 30 & 30 & 60 & \\
\hline \multirow{3}{*}{24} & 0 & 29 & 17 & 46 & \multirow[t]{3}{*}{$<0.001$} \\
\hline & 1 & 1 & 13 & 14 & \\
\hline & Total & 30 & 30 & 60 & \\
\hline \multirow{4}{*}{48} & 0 & 28 & 16 & 44 & \multirow[t]{4}{*}{0.002} \\
\hline & 1 & 2 & 12 & 14 & \\
\hline & 2 & 0 & 2 & 2 & \\
\hline & Total & 30 & 30 & 60 & \\
\hline
\end{tabular}

As depicted in table 3, there was a greater incidence of sedation in pethidine treated group compared to ketorolac group. The difference was statistically insignificant at 1 hour postoperatively $(\mathrm{p}=0.061)$. The difference was statistically significant at 6 hours postoperatively $(\mathrm{p}=0.045), 12$ hours postoperatively $(\mathrm{p}=0.010), 18$ hours postoperatively $(\mathrm{p}=$ $0.002), 24$ hours postoperatively $(\mathrm{p}<0.001)$ and 48 hours postoperatively $(\mathrm{p}=0.002)$.

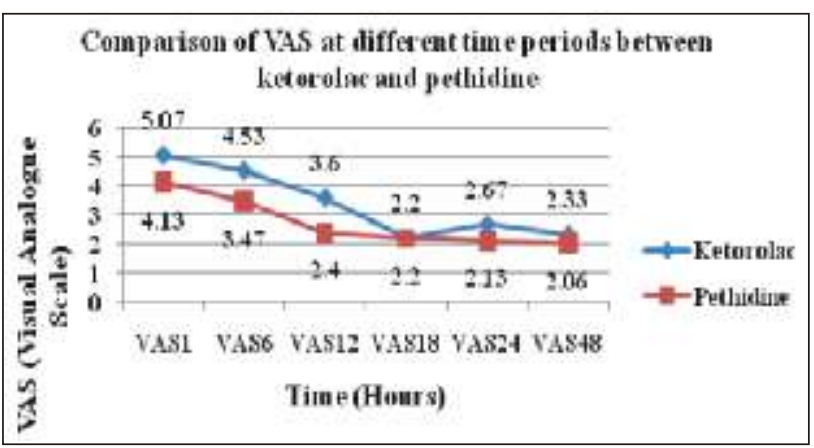

Figure 3. Graph showing VAS at different time periods between ketorolac and pethidine 


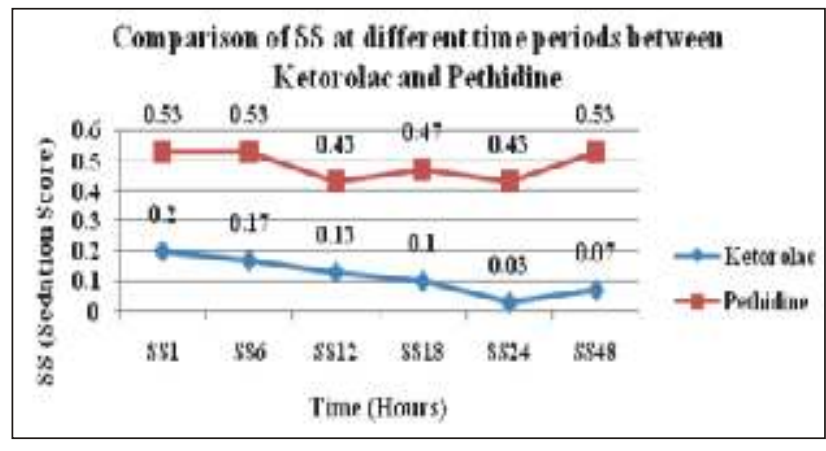

Figure 4. Graph showing sedation score at different time periods between ketorolac and pethidine.

\section{DISCUSSION}

Postoperative pain control is one of the most important aspects of management of surgical patients. Various drugs which are used to control the post-operative pain are mainly categorized into two groups i.e., nonsteroidal anti-inflammatory drugs and opioid. Different pain models have been used to evaluate the efficiency of different members of these two groups.

The present study was prompted by reported differences in the analgesic efficacy and sedative effect between ketorolac and pethidine in the postoperative pain management and was conducted with the goal of evaluating and comparing the above mentioned parameters.

In the present study, the analgesic efficacy (as measured by VAS score) of pethidine was superior (i.e., significantly lower mean VAS score and $\mathrm{p}<0.05)$ to ketorolac at $1,6,12$, and 24 hours postoperatively. This finding is comparable to the findings of the studies by Buran et $\mathrm{al}^{11}$, Walker et $\mathrm{al}^{18}$. However, it is contrary to the findings of the studies by Abbas et $\mathrm{al}^{22}$, Satku et $\mathrm{al}^{23}$, Stanski et $\mathrm{al}^{16}$, Fricke et $\mathrm{al}^{15}$, Henderson et $\mathrm{al}^{21}$, Gillis et $\mathrm{al}^{20}$ and Gin et $\mathrm{al}^{19}$ who suggests comparable (not significantly different) analgesic efficacy of these two drugs. Moreover, studies by De Andrade et $\mathrm{al}^{14}$, Henderson et $\mathrm{al}^{21}$, Oosterlinck et $\mathrm{al}^{13}$, Lane et $\mathrm{al}^{12}$ suggests greater efficacy of ketorolac than pethidine, the finding in contradiction to that of the present study.

However, at 18 and 48 hours, there was no significant difference in the mean VAS score $(\mathrm{p}>0.05)$. This finding was consistent with that of the study done by Burhan et $\mathrm{al}^{11}$. The incidence of sedation in patients using pethidine was significantly higher $(\mathrm{p}<0.05)$ than ketorolac during the entire period $(1,6,12,18,24,48$ hours postoperatively). This suggests that pethidine had pronounced sedative effect. This is due to depressant pharmacological action of pethidine on CNS.

\section{CONCLUSION}

In the present study, the analgesic efficacy (as measured by VAS score) of pethidine was superior (i.e., significantly lower mean VAS score; $\mathrm{p}<0.05$ ) to ketorolac at 1, 6, 12, and 24 hours postoperative. However, at 18 and 48 hours, there was no significant difference in the mean VAS score $(\mathrm{p}>0.05)$. The incidence of sedation in patients using pethidine was significantly higher $(\mathrm{p}<0.05)$ than ketorolac during the entire period $(6,12,18,24,48$ hours postoperatively).

As evident from the present study, pethidine seems to have better analgesic efficacy as compared to ketorolac. However, ketorolac can be considered a safer alternative to pethidine with lesser sedative effects. Likewise, the findings of the present study are comparable with other studies and can be used as supportive evidence for further studies. Nevertheless, a simple prospective study such as this is likely to suffer from biases regarding randomness, sample size, etc. Therefore, more standard randomized clinical trials are warranted for better assessment of analgesic efficacy and adverse effects between these two drugs.

\section{REFERENCES}

1. Raj PP. Taxonomy and classification of pain. The handbook of chronic pain. 2007:41-56.

2. Sutters KA, Levine JD, Dibble S, Savedra M, Miaskowski C. Analgesic efficacy and safety of single-dose intramuscular ketorolac for postoperative pain management in children following tonsillectomy. Pain. 1995 Apr 1;61(1):145-53.

3. Hamza AM, Hayat UM, Khan QA. To compare the efficacy of ketorolac and pethidine for postoperative pain relief in first 24 hours after tonsillectomy. Pakistan Journal of Medical and Health Sciences. 2012 Apr;6(2):326-8.

4. Carney DE, Nicolette LA, Ratner MH, Minerd A, Baesl TJ. Ketorolac reduces postoperative narcotic requirements. Journal of pediatric surgery. 2001 Jan 31;36(1):76-9.

5. McMahon SB, Koltzenburg M. Tracey I, Trunk D Wall \& Melzack's Textbook of pain : Expert consult online and Print Elsevier Health Services, 2013 Jun 21.

6. Uddin MB, HossainAM, Alam MM, Hossain AS. Ketorolac and pethidine in post-operative pain relief. Bangladesh Journal of Pharmacology. 2007;2(1):35-42.

7. Swadia VN, Shah MB. Comparative evaluation of ketorolac, tramadol and diclofenac for postoperative pain relief in minor surgical procedures. Indian J Anaes. 1999;43:64-6. 
8. Morrison CE, Dutton D, Howie LL. Pethidine compared with Meptazinol during labour. Anaesthesia. 1987;42:7-14.

9. Kulacoglu H, Alptekin A. Current options in local anesthesia for groin hernia repairs. Acta chirurgica Iugoslavica. 2011;58 (3):25-35.

10. Kehlet H, Holte K. Effect of postoperative analgesia on surgical outcome. British journal of anaesthesia. $2001 \mathrm{Jul}$ 1;87(1):62-72.

11. Md. BurhanUddin, A.K.M. MosharrofHossain, Meer MahbubulAlam, A.Z.M. Shakhawat Hossain. Ketorolac and pethidine in post-operative pain relief. Bangladesh J Pharmacol. $2007 ; 2: 35-42$.

12. Lane GE, Lathrop JC, Boysen DA, Lane RC. Effect of intramuscular intraoperative pain medication on narcotic usage after laparoscopic cholecystectomy. Am Surg. 1996; 62(11): 907-10.

13. Oosterlinck W, Philp NH, Charig C, Gillies G, Hetherington JW, Lloyd JA. Double blind single dose comparison of intramuscular ketorolac tromethamine and pethidine in the treatment of renal colic. J Clin Pharmacol. 1990; 30(4):336-41.

14. De Andrade JR, Maslanka M, Reines HD, Howe D, Rasmussen GL, Cardea J, Brown J, Bynum L, Shefrin A, Change YL, Maneatis T. Ketorolac versus Meperidine for pain relief after orthopaedic surgery. Clin Orthop Relat Res 1996; (325):301-12.

15. Fricke JR Jr, Angelocci D, Fox K, McHugh D, Bynum L, Yee JP. Comparison of the efficacy and safety of ketorolac and meperidine in the relief of dental pain. J Clin Pharmacol. 1992 Apr; 32(4):376-84.

16. Stanski DR, Cherry C, Bradley R, Sarnquist FH, Yee JP. Efficacy and safety of single doses of intramuscular ketorolac tromethamine compared with meperidine for postoperative pain. Pharmacotherapy.1990; 10:40-44.

17. Liu S, Carpenter RL, Neal JM. Epidural Anesthesia and Analgesia their role in Postoperative outcome. The Journal of the American Society of Anesthesiologists. 1995 Jun 1;82 (6):1474-506.

18. Walker JJ, Johnston J, Fairlie FM, Lloyd J, Bullingham R. A comparative study of intramuscular Ketorolac and Pethidine in labour pain. European Journal of Obstetrics, Gynecology, and Reproductive Biology. 1992,46(2-3):87-94

19. Gin T, Kan AF, Lam KK, O'Meara ME. Analgesia after caesarean section with intramuscular Ketorolac or Pethidine. Anaesth Intensive Care. 1993;21(4):4203.

20. Gillis JC, Brogden RN.Ketorolac.A reappraisal of its pharmacodynamic and pharmacokinetic properties and therapeutic use in pain management.Drugs. 1997 Jan; 53(1):139-88.

21. Henderson SO, Swadron S, Newton E. Comparison of intravenous ketorolac and meperidine in the treatment of biliary colic. J Emerg Med. 2002; 23(3):237-41.
22. Abbas SM, Kamal RS, Afshan G. Effect of ketorolac on postoperative pain relief in dental extraction cases a comparative study with pethidine. J Pak Med Assoc. 2004 Jun; 54(6):319-22.

23. Satku K, Lai FO, Kumar VP, Pereira BP, Chhatwal V. Singleblind comparative analgesic and safety study of single doses of intramuscularly administered ketorolac tromethamine and pethidine hydrochloride in patients with pain following orthopaedic surgery. Ann Acad Med Singapore. 1994 Nov; 23(6):828-31. 